\title{
Values stop play? Teachers' attitudes to the early years outdoor environment
}

Article

Accepted Version

Bilton, H. (2020) Values stop play? Teachers' attitudes to the early years outdoor environment. Early Child Development and Care, 190 (1). pp. 12-20. ISSN 1476-8275 doi:

https://doi.org/10.1080/03004430.2019.1653548 Available at https://centaur.reading.ac.uk/86411/

It is advisable to refer to the publisher's version if you intend to cite from the work. See Guidance on citing.

To link to this article DOI: http://dx.doi.org/10.1080/03004430.2019.1653548

Publisher: Informa UK Limited

All outputs in CentAUR are protected by Intellectual Property Rights law, including copyright law. Copyright and IPR is retained by the creators or other copyright holders. Terms and conditions for use of this material are defined in the End User Agreement.

\section{www.reading.ac.uk/centaur}

\section{CentAUR}

Central Archive at the University of Reading

Reading's research outputs online 


\title{
Title: Values stop play? Teachers' attitudes to the early years outdoor environment
}

\author{
Professor Helen Bilton \\ University of Reading, UK \\ h.o.bilton@reading.ac.uk
}

https://orcid.org/0000-0002-2001-2530

Helen Bilton is Professor of Outdoor Learning and Director for the Postgraduate Taught Programmes at the University of Reading.

\section{Abstract}

This paper explores the views and attitudes of a small group of teachers concerning the early years outdoor teaching and learning environment. Further their responses are compared to an online survey of teachers examining their attitudes to the early years outdoor environment. This extends the current knowledge as to the drivers for teachers' professed actions when working in the early years outdoor environment, and specifically the extent to which the teachers' own experiences of outdoors influences their professed behaviours in their role when working outside with children. At the heart of this discussion is the concern that only those teachers who have had good experiences of outdoor play themselves may go on to provide good outdoor experiences for young children.

Key words: outdoors, values, outdoor education, decision making, attitudes, early years, aims

\section{Introduction}

This study came about as a result of a previous piece of research conducted by myself (Bilton $2014 \mathrm{a}$ and b) which gathered qualitative and quantitative data through an online survey, concerning teacher attitudes and behaviours to the early years outdoor environment. Of the 350 schools contacted, 184 completed the survey, giving a 53 per cent response rate. A number of themes were generated from the results and alongside the range of responses from very detailed to scant, it was decided that trying to gain greater understanding from some of the respondents would be beneficial. This was achieved by interviewing 10 of the original respondents. This paper reports on the findings from those interviews.

\section{Framework for the study}

Teaching is a complex business. Shulman (1987) describes it as a complex act, with the need to have subject content knowledge, pedagogical content knowledge and pedagogical knowledge. So knowing that and knowing how are equally important. In other words, a teacher needs to have subject or domain knowledge, the knowledge to then teach that subject and finally the knowledge to teach. This act of teaching is even more complex for early years and primary teachers who need to know more than any other phase of teaching as they have to have pedagogical content 
knowledge as well as subject knowledge for a number of subjects: Mathematics, English, Science, art and design, computer science, design and technology, geography, history, languages, music, PE, religious studies and citizenship. Albeit the actual statutory curriculum for the under -fives in England is divided into seven areas for learning rather than 12 discreet subjects, they are communication and language, physical development, personal, social and emotional development, literacy, mathematics, understanding the world (including the STEM (Science, Technology, Engineering and Mathematics) subjects) and expressive arts and design. Another added complexity is that for early year practitioners they are expected to act in two different learning environments, that of inside and out, thereby needing to have pedagogical knowledge of the outdoors and subject content knowledge (eg: environmental and scientific). So all in all there is a lot to understand when an early years teacher. What drives the decisions these teachers make is important to know. With this in mind, I return to my previous piece of research.

An important finding from the previous study was that teachers (just over half) found it difficult to offer the why of what they do in the outdoor environment (Bilton 2014 a). It was suggested that possibly this lack of attention to the aims of education may not be through some ill intent rather simply a lack of attention to aims, with more focus being given to what is described as 'best practice'. However, the danger of paying attention to best practice is that it does not provide the prospect of understanding basic principles (Stephen 2012), and further, Browne (2004) talks about best practice being seen as the 'the truths' (p157), one could almost describe this as a dogma, which can in fact be misinterpreted and create poor practice. She cites the example of 'the naturally developing child' which has given rise to the idea of free choice and children following their interests with little adult interactions. But what this has actually led to is for some children having no choice and some children dominating the environment. Pollard (2008) challenges all those in education to consider their position concerning aims, arguing that we need to know our 'value position' (Pollard, 2008, p. 125) as this acts as a measuring tool, to check we are being consistent within our school setting, to check external pressures and to check our actual practice.

My own interest in the outdoor environment for learning has always made me consider why one person will allow something where another member of staff would not and to wonder whether it has something to do with this 'value position'. By value is meant that which we consider as important. If we see something as part of a value system or that we value it, it follows that we will promote it. Beliefs and values are built up over time through all our experiences but in particular our family and peer relationships. Values can change over time. They will also be swayed by the values of the setting in which we work. By way of example, I offer a discussion about risky play. Sandseter (2009a and b) and Waller, Sandseter, Wyver, Arlemalm-Hagser \& Maynard, (2010) note how the adult imposes their own will on children's behaviour and whether they will allow 'risky' play is based on their view of the child - whether children are seen as 'competent' or 'vulnerable' (Waller, Sandseter, Wyver, Arlemalm-Hagser \& Maynard, 2010, p. 441). Those who would not allow risky play do not believe in its value. The authors through their studies indicated that in part the adult is reliant on their own values and belief system to dictate what children can and cannot do when playing.

By carrying out in depth interviews with a group of early years teachers it was hoped to add to the knowledge as to the drivers for the teachers' professed actions when working in the early 
years outdoor environment, and specifically the extent to which the teachers' own experiences of outdoors influenced their professed behaviours in their role outside.

\section{Methodology}

\subsection{Research design}

The previous survey was not asking about the minutia of each day's action but rather about the views and attitudes of the teachers, and the facilities they had within their particular setting. It reported on what they said but this could not be construed as actual behaviour. A number of themes emerged from the analysis of the data. Those responses were further analysed and categorised into those who appeared positive towards outdoor education and those who did not. A sample of those presenting as either feeling positively or negatively toward outdoor education were approached for a follow up semi structured interview and those responses were both compared with each other to extract themes and with the findings from the previous study.

\subsection{Participants}

The participants came from schools within the University of Reading partnership. All of which were involved with the education of four to five year olds. This University is engaged with initial teacher education and training and therefore works with schools in its geographic area, covering eight local authorities. These partnership schools have strong relationships with the university and were contacted originally as potential participants for the survey, giving a convenience sample. The range of educational settings in the sample included small rural schools, urban and community schools, small and large nursery schools, children's centres, large and small primary schools and infant schools with a range of cultures and languages. Of 350 schools contacted 184 replied giving a 52.6 per cent return rate. Respondents for this present study were chosen by analysing the 184 respondents' replies to the previous study and those which presented as either positively or negatively towards outdoor education or those who offered interesting, contradictory or surprising replies were selected to be interviewed. Of those respondents 20 were contacted via the head teacher email to request participation in a follow up interview. Where no initial response was forthcoming, I emailed again, then emailed the administrative email, then rang the school a further two times. Once the school consent had been given the contact was passed to the teacher who had completed the on-line survey originally. Of those 20 , ten replied to agree to be interviewed, therefore giving a 50 per cent return rate. Each interview lasted on average 25 minutes producing 250 minutes of transcribed conversation.

\subsection{Instruments}

Wishing to discover the participants' views and attitudes around the themes generated in the original survey meant that a semi-standardised interview was adopted. A semi standardised interview was also adopted as there were quite particular themes to be explored. It has to be acknowledged, however, that attitudes are not necessarily equated with behaviour, they can only be an indicator of behaviour (Simmons, 2008 p. 209). The interview questions comprised both open and closed elements organised into 16 questions. They included basic information such a training phase and age and more specific questions such as views as to whether the outdoor environment is important to some or all children. One hypothetical question was also asked (See Appendix 1). The questions were asked in identical order for each participant but there were supplementary questions or probes when participants struggled to answer the question. Interviews were offered either face to face or over the phone. As the researcher and participants were familiar with each 
other and the questions were not construed to be of a sensitive nature, the detachment of the telephone conversation was not seen as a barrier to achieving responses to the questions. All interviews, regardless of type, were pre- arranged. Eight selected a telephone interview and two a face to face interview. An information sheet outlining the purpose of the interview and a copy of one of the papers reporting on the previous survey findings were provided prior to the interview, but the participants were not sent the questions in advance. Ethical approval from the university ethics board was obtained. Each interview was audio recorded and I also wrote notes. The interview questions were piloted with two teachers not involved with the research and from this adaptations were made to two questions.

\subsection{Analysis}

There were two approaches employed to analyse the data from these interviews, deductive and inductive. Deductive methods were employed initially using the themes which had emerged from the original survey. These were themes to be tested. This indicated where several respondents had replied in a similar way or not, where a theme had been contradicted or supported. Inductive methods were then used to identify and analyse those themes which I had not considered. Each response was then purposefully compared to others within the code category and across the response-set for the similarity of responses within each code and the distinction between each code. The resulting data was read through several times to check the strength of coding and one month later re-coded, achieving a 90 per cent inter-related reliability.

\subsection{Limitations}

I am well known to staff within partnership schools and had worked closely with many of them. Of the ten participants I knew professionally nine of them reasonably well. I tried to ensure the questions asked did not necessarily fit with views I might be considered to have. For example a question such as 'is the environment a teaching or learning environment?' can offer three alternatives and all of which the author has shared in her texts. Asking about the participants' decision making processes is a relatively new field to me and therefore the response could not be influenced by my views. Only the question 'is the environment for some or all children?' might have been influenced by giving what would be construed the appropriate response.

\section{Results and Discussion}

\subsection{Those who responded to the request to participate in an interview}

The first interesting finding is what type responded to being interviewed. Twenty original respondents to the survey were approached to complete a follow up interview and as indicated in section 3 , the participants were approached in a number of ways and repeatedly in the hope they would participate in an interview. Of those who answered and agreed to be interviewed all had expressed support for the outdoor environment in the original survey. The ten who did not respond, despite repeated contact attempts, were all respondents who had indicated a negative attitude to the environment. For example, they offered disinterested replies or incomplete replies, presented problems to working outside, suggested that the role of the adult outdoors was about 'crowd control'. In contrast those who agreed to be interviewed indicated in the original survey that they were passionate about outdoor play, gave considerable detail to the answers and offered interesting solutions to issues. 
Therefore, a significant finding from this study is that those participants who had indicated a lack of interest in education out of doors were not interested in being interviewed. So personal experience would appear to have impacted respondents' decision to help with this research. It could be that they had not thought through their values about the outdoor environment and so may have been unwilling to have this uneasy void probed.

\subsection{Personal and professional experience}

The participants' years of teaching experience ranged from $6-28$ years, and the years of experience in the early years ranged from $10-29$ years. The participants training age phases were one of the following: 3-5 years, 3-7 years, 3-8 years, 3-9 years, 3-11 years, 4-8 years and 8-13 years.

In terms of training for early years outdoor education there had either been no training, or limited related to PE or physical development (two participants). So the knowledge about the utilisation of the outdoor environment was extremely limited. Two interviewees had knowledge of outdoors and science through their first degree, one in biological sciences and one completing her dissertation on a geographic related matter.

In terms of experience of outdoor education once qualified there were two clear responses, either the respondent had had very good first job experience of outdoor provision, this was the case for two people or the other response was that there had been no outdoor provision when they first started work and it was only in later years where they were in schools who 'did' outdoors that their knowledge grew.

A finding from this might be that school experience matters regarding whether one utilises outdoor education.

\subsection{Knowledge of the outdoor environment}

Personal knowledge and experience of outdoors for all the participants was extensive. All had had experience of being outside from an early age, including living in an area where one could spend time away from the house, having a large garden, being taken: for walks, to the seaside, and more remote areas such as the Brecon Beacons and on the family boat. Many types of outdoor environments were mentioned: parks, gardens, beach, streams and the sea, farm, woods, the street. What was done outside included the more structured day out, being on the boat, holidaying, to the more unstructured role play, 'trapeze shows', doing handstands, riding bikes, playing in the coal bunker, playing in trees, digging a fish pond, games with apples, dog walking, Pooh sticks, making camps, black-berrying. For one interviewee she remembers her Dad took her on the canal when it was frozen. Another talked about a 'death slide' set up in the garden, and another about being a long way away from home and the requirement to only return when the street lights went on. One interviewee lived in an un-adopted street, while another lived near an army camp where there was access to a good deal of open space. All participants mentioned their parents and/or grandparents love for the outdoors, for example, the grandparents who had a lot of land, a grandfather who instilled a love of nature, parents who loved outdoors, the garden and walking, parents who did a lot of boating. Mention was made of parents who were not bothered about their children getting dirty or messy. One participant remembers the family being out every weekend with the Dad planning the day. All mentioned not only other adults when discussing their experiences but also other children, be it friends or siblings. 
Overall, the enthusiasm with which these adults who ranged in age from 36 to 56 years, talked about their childhood experiences, was palpable and what they said they had experienced as children was substantial outdoor experience alongside interested adults.

\subsection{Aims for outdoor education}

In the original survey under half of the 184 replies could offer an aim and of those 15 coded responses identified, nine could be described as the action of practice not an aim. In this study disposition for learning/ personal development were mentioned by five respondents, physical development and activity by four, all areas of the curriculum by one and exploration of the natural world, scientific and environment study by two and language development by one. Respondents were also asked whether the aims were the same or different to inside and the replies were that they were the same but with caveats. One response said that the skills learnt inside could be applied outside, another that the aims were on a bigger scale outside compared to in, and another, that the resources were different outside to achieve the overall aims. The action of practice responses which did not fulfil the definition of an aim included helping children to learn, having more space, teaching the next steps in learning.

Overall, the respondents' answers to this question mimicked the lack of understanding of the respondents to the original survey. Some were able to see that an aim is about purpose and a developmental need, eg: physical development, but many couched them in terminology which was not clear, for example fresh air was seen as an aim. The umbrella for such a statement would be physical well being, but the respondent could only list a quite specific part of physical development. Another talked in terms of weather and seasons which comes under the heading exploration of the natural world, scientific and environment study.

\subsection{Challenges of working outside}

From this study a range of challenges to working outside were identified, all challenges were also apparent in the literature.

Every respondent from this study mentioned other adults, including the headteacher and their attitude to outside as being the main challenge when working outside. These attitudes were described as staff: dislike of outside, not liking being cold, not having personal experience of working outside, lack of understanding of how to behave outside. One interviewee actually talked in terms of some staff being 'terrified' of outside. Staff attitudes was not a finding from the original online survey, where the concern was not about staff attitudes but about a lack of staff in the environment and too many children for the space.

The weather and impact of the weather was mentioned as a concern by three respondents. This was viewed as a drawn back by 59 per cent of the original respondents to the survey. However, given that one of the main aims of the outdoors was cited as the exploration of the natural world there appeared a mismatch between this and the comment regarding the weather. It was surmised that possibly that it wasn't the weather but lack of suitable clothing, timetabling issues or lack of staff interest that caused staff to suggest the weather was a drawback to practice.

Parental attitudes was seen by two respondents as a problem. Noise from traffic (including aircraft) and nature was seen as a challenge. This was not a challenge I had considered previously. 
That some people felt money needed to be spent on the space, the look of the place and having enough people to manage in and out were all mentioned as drawbacks to practice.

From this survey, it seemed a summary could be that although the staff interviewed were supportive to outdoor education they found other staff's attitudes a drawback to outdoor play being successful. A drawback not previously considered by myself but worthy of comment was noise being a drawback and this does appear to be a growing concern, particularly from road and aircraft traffic.

\subsection{Personal values impacting what is done with children outside}

All the participants seemed to find this an easy question to answer and easily made links between their own childhood experiences and how they were with children in school. One participant talked about taking risks when she was younger and felt she learnt from these experiences and it gave her emotional confidence. She linked this to her work and said she wanted children in her care to gain that confidence and so tried to encourage them outside to take risks purposely and indeed this had been a subject of discussion amongst the staff. Another interviewee felt her own experience of outdoors made her confident and because she was 'good' outside this therefore enabled her to work confidently with children. Making potions (a harbinger of early chemistry) outside and digging (basic engineering) as a child was another interviewee's memory and she made a direct and causal link with these experiences to a 'pic and mix kitchen' she had created, where children could pick herbs, petals, leaves and mix with water to make 'potions'. As a child, another interviewee remembered having to make things (design and technology) they needed for their play and she said that she did this now, that is, adapts or makes do, and helps children to see that they do not need a ready -made environment but can create things they need in play. Another said from her childhood experiences meant she 'believed' in outdoors particularly such things as the sensory garden (environmental study). She followed this up saying she was the only member of staff who noticed the sensory garden and tended it. One interviewee mentioned the ' 100 things to do outside', a National Trust campaign, and she is now encouraging this approach at school. This has now spread to the class planning and once a week there is a challenge of something the staff should help the children to do or do with them, these included going to the park, climbing trees, flying a kite, paddling in the water (basic understanding of energy and force, which comes under physics). Finally, one interviewee said she wanted to build memories for the children in her class, because of the strong memories she had of her parents and grandparents who were so involved with them outside. She finished with saying: 'you don't remember all the brilliant TV programmes when thinking of childhood'.

Overall, these 10 participants in this small study were easily able to link their own childhood experiences and the activities they provide children within their present school setting. In their minds there was a causal link between their own experiences and what they did as a teacher. We cannot underestimate the impact of this in terms of the Science, Technology, Engineering and Mathematics (STEM) understanding of young children.

\subsection{Decision making processes when working outside}

Of the 10 , seven indicated that safety was an important consideration when making a decision. Otherwise the interviewees were quite clear what drove their decision making process knowledge of the children and their needs and interests and what to do next to help with their learning. One respondent mentioned decision making during planning time and that this was to do 
with curriculum areas and gaps in knowledge of children. One respondent went through her decision making process in detail and said that when making judgements she wanted children to take risks and measured this against whether they might get hurt, indicating that she was clear about her decision making process. She proffered an example of a young colleague who was afraid of risky play and the interviewee was trying to teach this particular member of staff to 'stop and think' before she immediately stopped children doing something. One respondent said that she felt all staff in the school had different views about where they felt danger was but everyone had to weigh things up and look at the learning potential of any activity, and that all staff were aware of this process of consideration. Another followed her answer up commenting that health and safety was about looking for danger that a child might not be aware of and it didn't necessarily mean stopping the activity. She gave the example of working out if something would fall on a child if it were placed at the wrong angle and therefore avoiding this by moving the object.

That some staff were able to articulate the process of thinking through their decision making process is a useful finding as it can sometimes be thought that those who are happier to let children take risks are somehow more carefree or nonchalant. A finding from the study of a Portuguese day care centre found that those staff who were very keen for young children (under two years) to take risks and saw the benefits to making mistakes were actually not as risk happy as might at first be thought. There were instances where the staff judged an activity to be dangerous and would remove the children from the activity (Bilton, Bento and Dias 2017).

\section{Discussion}

This study reported on the findings from ten interviews with early years teachers about their attitudes and beliefs to outdoor learning. Significant was the discovery that those teachers who chose to take part in the survey all reported having had extensive experience of playing outside as children and had adults around them who enjoyed the outdoors. Also significant was that respondents were able to make causal links between their own experiences as a child and approaches within the teaching setting. All respondents, even though they supported risky play, had the safety of the children as a high concern when considering the play. All respondents reported a lack of training to do with outdoor education, and a positive influence of later experiences of outdoor education in schools they worked in.

More difficult was for some of the teachers to articulate how they came to the decisions they did when working outside with children but some were able to quite meticulously detail how they had come to the judgements they did. The need for this level of articulation is further justified when analysing the ability to establish the aims for outdoor education which both these interviewees and the respondents to the original survey found tricky. Given the complexity of early years teaching, more needs to be done to help teachers articulate the aims of the education they present outside particularly when we think about using the outdoors for stimuli for investigations and/or as a living laboratory. This does suggest that more need to be done in terms of continuing professional development.

Those interviewed in this study found that a major drawback to outdoor education was the attitude of other staff, although this was not raised in the original survey. These staff who supported outdoor education indicated that the attitudes of others around them could impact what types of outdoor education took place. A drawback not previously considered by myself but worthy of 
comment was noise being a drawback to outdoor education and this does appear to be a growing concern, particularly from road and aircraft traffic, an issue raised initially by Shield and Dockrell in 2003.

This small - scale study indicates that the experiences we have in our own family will impact whether outdoor education will be positively supported. This finding supports a study completed in 2011 by Waite, in which she calls for a 'reawakening of values-based pedagogies' (p. 80). A recent study by Bilton and Waters (2017) indicate that the value underpinning curricular documentation does influence practice of teachers and again this supports the Waite (2011) study. Palmer (1997, p.14) argues that 'we teach who we are' and the way we behave reflects our inner values. This is an important issue and even more crucial when we consider the STEM subjects and centrality of these subjects to our futures. There are fewer opportunities afforded children to play outside now and these children will become adults. If those adults become teachers and they have little training or setting experience of outdoor learning, does this mean their 'value position' will mean the inevitable demise of the early years outdoor teaching and learning environment?

\section{Bibliography}

Bilton, H. (2014b). What is outside? The Early Years Foundation Stage in England: Outdoor facilities, organisation and staff attitudes. American Journal of Educational Research, 2, 10, 942-949. doi:10.12691/education-2-10-14.

Bilton, H. (2014a). The aims of early years outdoor education in England: A conceptual and empirical investigation. International Journal of Education and Social Science, 1, 3, Oct, 38-50.

Bilton, H., Bento, G. \& Dias, G. (2017). Taking the first steps outside. Under threes learning and developing in the natural environment. Abingdon: Routledge.

Bilton, H. \& Waters, J. (2017). Why take young children outside? A critical consideration of the professed aims for outdoor learning in the early years by teachers from England and Wales. Social Sciences, 6 (1). 1. ISSN 2076-0760.

Browne, N. (2004). Gender equity in the early years. Maidenhead: Open University Press.

Palmer, P. (1997). The heart of a teacher: Identity and integrity in teaching. Change. 29, 6, 14-21.

Pollard, A. (2008). Reflective teaching. London: Continuum International Publishing Group.

Sandseter, E. (2009a). Children's expression of exhilaration and fear in risky play. Contemporary Issues in Early Childhood, 10, 2, 92-106. doi: 10.2304/ciec.2009.10.2.92

Sandseter, E. (2009b). 'Characteristics of risky play'. Journal of Adventure Education and Outdoor Learning, 9 , 1, 3-21.

Shield, B. and Dockrell, J (2003). The effects of noise on children at school: a review. Building Acoustics 10(2), 97-106.

http://citeseerx.ist.psu.edu/viewdoc/download?doi=10.1.1.629.1932\&rep=rep1\&type=pdf 
Shulman, L. S. (1987). Knowledge and teaching: Foundations of the new reform. Harvard Educational Review, 57, 1- 22.

Simmons, R. (2008). Questionnaires. In Researching Social Life, 3rd ed., edited by N. Gilbert, 3rd ed. London: Sage Publications Limited. 182-205.

Stephen, C. (2012). Looking for theory in preschool education. Studies in Philosophy and Education, 31, 227- 238. doi:10.1007//s11217-012-9288-5.

Waite, S. (2011). Teaching and learning outside the classroom: personal values, alternative pedagogies and standards, Education 3-13, 39:1, 65-82, DOI: 10.1080/03004270903206141

Waller, T., Sandseter, E., Wyver, S., Arlemalm-Hagser, E., \& Maynard, T. (2010). The dynamics of early childhood spaces: opportunities for outdoor play. European Early Childhood Education Research Journal, 18 (4), 437-443. doi:10.1080/1350293X.2010.525917. 
Appendix 1 The interview questions

\section{The Early Years Foundation Stage outdoor environment: teacher attitudes. Questions}

Can you tell me a little bit about yourself: professional and personal

\begin{tabular}{|l|l|}
\hline Number of years in teaching & \\
\hline Training phase & \\
\hline Age & \\
\hline $\begin{array}{l}\text { Number of years' experience with early } \\
\text { years }\end{array}$ & \\
\hline Personal knowledge of outdoors & \\
\hline $\begin{array}{l}\text { Professional knowledge and experience of } \\
\text { outdoors- training, schools, people }\end{array}$ & \\
\hline
\end{tabular}

Would you say the outdoor environment is more of a learning environment or a teaching environment? And what makes you say this? (trying to unpick whether just about formal curriculum or about dispositions for learning or both- related to Wales and English study)

From your experience what do you personally see as the challenges of working outside with young children? (I suspect weather, risk, staffing, facilities will come up here - all mentioned as problems in questionnaire)

What is your priority concern inside the classroom and what is your priority concern when in the outdoor environment? (trying to elicit the risk issue here, if they don't bite then ask: Do you put any restrictions on outdoor activity and why?)

Is the outdoor environment relevant to all children or only some? (so this is the issue re 'only for boys')

What are the aims or purposes of outdoor education and are they different to working inside with children? (so this is about language development, etc, I have put the word 'purpose' in as I don't think many people really got the concept 'aim')

Could you give me some examples of the equipment or activities you offer to fulfil those aims? (so this is about match or mismatch of aims and facilities)

What emphasis do you place on oral language development when in the outdoor environment and what facilities do you provide? (so trying to get what they do to encourage oral language)

In what ways do you think your own personal values impact what you do with children outside? Can you give an example?

I want to ask you about your understanding of your own decision making processes when working outside. When you make decisions about what you do outside or enable children to do what do you think impacts that process? (so this is about trying to draw their understanding of what restricts them)

If you had a silver wand and could do whatever you wanted in the outdoor environment 
what would that be? Why don't you do those things now? (so wanting to know what they are really like, not talking about 'I would have a swimming pool' answer but really if they are restricted now and by what) 